\title{
EDITORIAL
}

\section{Corticosteroids in sarcoidosis: friend or foe?}

\author{
R.M. du Bois
}

Sarcoidosis is a chronic, multiorgan disorder of unknown aetiology, characterized in affected organs by an accumulation of T lymphocytes and mononuclear phagocytes, noncaseating epithelioid cell ("immune") granulomas and tissue injury [1-3]. The general paradigm of immune granuloma formation suggests a specific, T-cell-mediated response to an antigenic agent that has been processed by macrophages and presented to antigen-specific $\mathrm{T}$ lymphocytes. The T-cell, in turn, directs the accumulation and differentiation of mononuclear phagocytes in the local microenvironment $[1,2,4]$. The disease can present in an acute or subacute form and is often selflimited, but in many other cases it is chronic, with variable disease activity over many years.

Corticosteroids have been the mainstay of treatment for more than $30 \mathrm{yrs}$, but there is still argument about their place in management. This is coupled to a certain nihilism about a group of drugs of which the side-effect profile is receiving increasing publicity. Whilst it is entirely appropriate that potential benefits of a treatment should be balanced against the risk of side-effect and must be discussed fully with each patient, the enormous benefits gained by many patients with chronic inflammatory diseases must also be part of that discussion.

The aim of this article is to review the use of corticosteroids in sarcoidosis, with particular emphasis on persistent pulmonary disease, by addressing three issues: 1) Is corticosteroid therapy a rational approach?; 2) Do they modulate disease?; and 3) Do they affect long-term outcome?

\section{Is corticosteroid therapy a rational approach?}

The rationale on which sarcoid therapy is based centres on the considerable advances which have been made in the understanding of the pathogenesis of the disease over the last decade, and owes much to the advent of cellular and molecular methodologies. An overview of the critical components of pathogenesis is necessary to put into perspective the goals of treatment.

\section{Pathogenesis of sarcoidosis}

\section{Aetiology}

There is abundant evidence to support the concept that sarcoid granulomas are formed in response to a persis-

R.M. du Bois, Royal Brompton Hospital, Emmanuel Kaye Building, Manresa Road, London SW3 6LR, UK. tent, poorly degradable, antigenic stimulus. Firstly, immune granulomas are known to form in response to persistent antigenic epitopes present after infection with organisms, such as schistosomiasis or mycobacterial infection. Secondly, pulmonary immune granulomas may be initiated by infectious agents, inorganic agents, and organic particulates: the factor common to all this is their low biodegradability and/or persistence, often within macrophages [5].

The cause of sarcoidosis has been sought for almost 100 yrs. Historically, a relationship with tuberculosis akin to the two forms of leprosy (multibacillary lepromatous disease and paucibacillary tuberculoid disease) has been suspected, but never substantiated. The issue has been given new life by the application of molecular biology techniques. Using mycobacteria-specific primers and the polymerase chain reaction, mycobacterial deoxyribonucleic acid (DNA) molecules were identified in granulomatous tissue (lung skin or lymph node) in one study in 7 out of 16 cases, compared to 1 out of 16 normal controls, but in only 2 out of 4 tuberculosis controls [6]. A second study, by a different group, reported contradictory findings: tissue or cell samples from 16 sarcoidosis patients were compared with 13 control tissue samples, four normal bronchoalveolar lavage samples and 11 normal volunteer lavage samples. Most of the sarcoidosis samples were negative, using Mycobacterium hominis specific primers and a technique sensitive enough to detect two mycobacterial genomes - the equivalent of 15 organisms $\cdot 10^{-6}$ human cells [7]. It is also noteworthy that the coexistence of sarcoidosis and tuberculosis has been recognized for some time [8]. A final judgement on this issue will require more extensive investigations.

\section{T-cell triggering}

Whatever the nature of the initiating agent, it is recognized that the antigenic epitopes that drive T-cell responses are "hidden" in the tertiary structure of the native molecules, and are "exposed" by processing within the macrophage and other antigen-presenting cells and co-expressed, as small peptide fragments, on its surface, together with class II major histocompatibility complex (MHC) molecules $[9,10]$. This is in contrast to epitopes that drive $\mathrm{B}$ cell responses, which are usually on the external regions of the intact protein [10]. Dendritic cells are more potent presenters of antigen than alveolar macrophages. Class II MHC molecules are crucial for 
antigen presentation to CD4+ T-cell and, therefore, necessary for the subsequent development of a cell-mediated immune response [11-15].

In sarcoidosis, there is evidence that alveolar macrophages, in comparison to those from normal individuals, are capable of increased presentation of nonrelevant antigen, such as tetanus toxoid, to lymphocytes $[16,17]$.

Further evidence that lung macrophages are presenting antigens to T-cells in sarcoidosis comes from analysis of the numbers of T-cell surface antigen receptors on lung T-cells. Recognition of antigen-class II complexes by specific T-cell antigen receptors (TCRs) is an absolute prerequisite for an antigen to be capable of driving a T-cell response. One consequence of T-cell antigen receptor triggering is the downregulation of surface TCR molecules and the upregulation of TCR messenger ribonucleic acid (mRNA) transcript numbers [18, 19]. If TCR triggering occurs in sarcoidosis, it would be expected that T-cells from active disease sites would exhibit the appropriate surface and mRNA changes. This is the case: compared to blood T-cells, sarcoid lung Tlymphocytes exhibit a decrease in density of surface TCR molecules, and they express increased numbers of TCR $\beta$-chain mRNA transcripts [20]. This downregulation of TCR may explain the reduced proliferative response of lung T-cells to recall antigens than lung cells obtained from normal individuals [21].

\section{Consequences of $T$-cell triggering}

There are a number of results of the initial direct macrophage T-cell interaction, which are of importance in the development of the granuloma. These involve the expression of a number of cell surface molecules on macrophages and lymphocytes and their release of key cytokines.

\section{Mononuclear phagocytes}

There is evidence from a variety of sources that the mononuclear phagocytes participating in the granulomas in sarcoidosis are recruited both from the blood and from local proliferation, and are activated [22-26]. In this respect, studies of lung macrophages using monoclonal antibodies have demonstrated that the cells bear the phenotype of young, recently recruited monocytes [22, 26]. The pulmonary mononuclear phagocyte population in sarcoidosis is also proliferating at a rate that is two to three times normal [23]. Consistent with the concept that lung mononuclear phagocytes are activated, the surface density of all categories of class II MHC molecules is increased on these cells [24, 25].

Macrophage cytokines are almost certainly involved in the development of sarcoid granulomas, although the evidence for this is not unequivocal. Evaluation of the release of interleukin-1 (IL-1) by alveolar macrophages from individuals with sarcoidosis has led to conflicting reports; some studies show no increase, compared with controls [27-29]. Of two more recent studies, one has shown that alveolar macrophages from patients with sarcoidosis spontaneously secrete IL- 1 , tumour necrosis factor- $\alpha(\mathrm{TNF}-\alpha)$ and prostaglandin $\mathrm{E}_{2}\left(\mathrm{PGE}_{2}\right)$, but that the amounts secreted from patients with active disease did not differ significantly from patients with inactive disease [30], whereas, the second study demonstrated IL-1 secretion only in "active" disease [31].

Spontaneous alveolar macrophage secretion of TNF$\alpha$ has been found to be increased in patients with sarcoidosis in three studies [31-33], but no different in another study [34]. However, when normal macrophages are cultured in the presence of IL-2, a cytokine known to be secreted spontaneously by lymphocytes obtained from the lower respiratory tract of patients with sarcoidosis, increased amounts of TNF $\alpha$ mRNA transcripts are found [35]. Because lung CD4+ MHC class II+ Tcells are releasing IL-2 in sarcoidosis [36], it is possible that CD4+ T-cells are activating genes, such as TNF $\alpha$, in lung macrophages in this disease. Other macrophage products which are released from cells obtained from sarcoidosis patients include the granulocyte colony- stimulating factor (G-CSF) (inducer of granulopoiesis and neutrophil activation) [37].

\section{Lymphocytes}

Because the aetiology of sarcoidosis is unknown, the major evidence that the granulomas are immune-based comes from analysis of the lymphocyte populations from lavage and tissue samples. Although sarcoidosis is a systemic disorder, the lymphocyte populations are strikingly compartmentalized. At sites of disease activity, such as the lung, there is a marked expansion in lymphocyte numbers, whereas in the blood there is a lymphopenia [38]. Consistent with the concept of compartmentalization, the lung lymphocytes are dominated by CD4+ T-cells, with the ratio of CD4+ to CD8+ populations within the lung being 3-10:1. In comparison, the CD4+ to CD8+ ratio in normal lung is $2: 1$; approximately $1-1: 5: 1$ in sarcoid blood, and 1.5-3:1 in normal blood [38]. The T-cells within the lung are proliferating spontaneously at an exaggerated rate, and show evidence of activation [39] and express the surface markers of activation, including high affinity IL-2 receptors (IL2R), human leucocyte antigen-DR (HLA-DR) class II MHC molecules, and the very late activation antigen-1 (VLA-1) marker of late activation [40-42]. Most T-cells are $\mathrm{CD} 45 \mathrm{RO}+$ (in common with normal lung T-cells) which denotes that they are of the "antigen-primed" subset of T-cells and are leu-8-. Furthermore, they can express the epitopes identified by the antibodies Ki67 and PCNA, which indicate that they are proliferating [43, 44]. This is consistent with the observation of spontaneous proliferation ex vivo in cells lavaged from patients with active disease. In contrast to lung, blood T-cells in active pulmonary sarcoidosis appear relatively quiescent, with no evidence of lymphokine release [45]. However, although some blood T-cells do express activation markers, such as IL-2R and class II MHC molecules, these cells probably represent T-cells which are activated in tissues, such 
as the lung, and which have migrated to blood [45, 46].

Antigen presentation, in association with secondary cytokine signals, stimulates $\mathrm{T}$-cells to release a number of lymphokines that activate macrophages and lymphocytes and provide the building blocks from which granulomas are formed [1, 2, 47]. The defined lymphokines of most relevance to the generation of granulomas are interleukin-2 (IL-2; the T-cell growth factor), and interferon-gamma (IFN- $\gamma$; a potent activator of macrophages). Consistent with this concept, monocytes and alveolar macrophages can be stimulated in vitro by IFN- $\gamma$ to increase the expression of class II surface antigens, Fc receptors, IL-2 receptors, and transferrin receptors. Furthermore, under appropriate circumstances, mononuclear phagocytes will form giant cells under the influence of IFN- $\gamma$. In addition, lung lymphocytes express mRNA for the granulocyte-monocyte colony-stimulating factor (GM-CSF; stimulator of granulopoiesis and monopoiesis) [48, 49], and monocyte colony-stimulating factor (M-CSF; stimulator of monocyte proliferation) [50]. The relative contributions of the lymphokines to granuloma formation are not known.

Tissue immunohistochemistry studies have confirmed that lavage cells are representative of those in the lung parenchyma [51, 52] and in situ hybridization has reinforced the concept that cytokines have important roles in the generation of immune granulomas. A detailed study of cytokine expression in lymph nodes has demonstrated the presence of IL- $1 \alpha$ and $\beta$, TNF $\alpha$, IL-2, IL-6, and IFN- $\gamma$ in situ; and, importantly, that there is a spatial arrangement of cytokine producing cells: IL- $1 \beta$, $\mathrm{TNF} \alpha$ and IFN $-\gamma$ are restricted to the granuloma itself, whereas the other cytokines are distributed in cells more randomly [53]. Strikingly, the most avidly expressed product was IL-1 $\beta$, whilst IFN- $\gamma$ was 32 fold more abundant than IL-2. These data are consistent with the concepts of spatial arrangements of cells in immune granulomas in sarcoidosis, defined by CAMPBELL et al. [51] and MunRo et al. [54] using monoclonal antibodies to identify cell phenotypes. It is against this background that we must assess the logic of treating the disease with corticosteroids.

\section{Corticosteroids}

This group of drugs has played a crucial role in the management of all forms of chronic inflammatory conditions affecting the lungs and other organs. Corticosteroids are now known to function by entering the cytoplasm of inflammatory cells and binding with steroid receptors located within the cytoplasm. The receptors exist in an inactive form, bound to two $90 \mathrm{kD}$ heat shock protein molecules. Following the association of steroid with steroid receptor, the heat shock protein molecules dissociate, thereby exposing a DNA binding domain. The steroid/receptor complex then enters the nucleus, where binding occurs to glucocorticoid response elements, generally located in the upstream promoter regions of cytokine and other genes resulting in modulation of gene transcription.

\section{Do corticosteroids modulate disease progression?}

Until the cause of sarcoidosis is identified and means found to eradicate the trigger from affected organs, the disease can only by controlled rather than cured. Corticosteroids have been the mainstay of treatment for over $30 \mathrm{yrs}$ and appear to be the most effective drug available, but what is the evidence that they modulate disease? This question can be answered in two ways; firstly, by showing that steroids affect important mechanisms of relevance to pathogenesis; and, secondly, by demonstrating an effect on clinical indices.

\section{Corticosteroids and pathogenesis}

Table 1 illustrates the major cell surface and cytokine targets of corticosteroids. From the table it can be seen that a number of genes which play important roles in the pathogenesis of sarcoidosis are modulated by corticosteroids. Of particular relevance are genes which are expressed soon after antigen triggering of CD4+ T-cells: IL-2, IFN- $\gamma$, IL- 1 and the IL-2 receptor IL-2R [55]. Other genes which may play important roles in pathogenesis by influencing the expression of cell adhesion molecules $(\mathrm{TNF} \alpha)$ and leucocyte/monocyte proliferation and activation (GM-CSF, G-CSF) are also regulated by corticosteroids [55-58].

There are, therefore, good data to suggest that steroids can impact on mechanisms important at an early stage of the pathogenic process.

\section{Corticosteroids and clinical efficacy}

Many studies have shown quite conclusively that steroids can improve chest radiographic features and lung function measurements, and these include some of those studies which conclude that there was no long-term benefit on disease outcome (but see below) [59-64]. OdLum and FITZGERALD [62] studied six patients who had been untreated for a period of $6.8 \pm 2.4$ yrs and whose disease was demonstrated to be progressing. On treatment with steroids, dyspnoea lessened, lung volumes and gas exchange improved, associated with improvements in chest radiography and gallium scans. In this group of patients defined by their chronicity, sustained improvement (mean of 22 months) was seen despite lengthy periods during which disease had deteriorated and no treatment has been given.

TURNER-WARWICK et al. [64] treated 32 patients with a standard treatment which was then titrated to maintain maximum improvement. Results showed that chest radiographs improved in all 32 and were not related to the initial BAL lymphocytes count.

ISRAEL et al. [61] studied 83 patients. Treatment consisted of three months of prednisone at $15 \mathrm{mg} \cdot \mathrm{day}^{-1}$. 
Table 1. - Cytokines, relevant to sarcoidosis, modulated by corticosteroids

\begin{tabular}{ll}
\hline Interleukin 1 and 2 & IL-1, IL-2 \\
Tumour necrosis factor- $\alpha$ & TNF $\alpha$ \\
Granulocyte-macrophage colony-stimulating factor & GM-CSF \\
Interferon- $\gamma$ & IFN- $\gamma$ \\
Interleukin-2 receptor & IL-2R \\
IL-1 inhibitor (increased) & \\
\hline
\end{tabular}

Significant improvement was seen in the treated group with Stage II and III disease by comparison with the untreated group, but no difference was observed in patients with Stage I disease.

SElroos and SELLERGREN [60] studied 39 patients with Stage II disease of less than 5 yrs' duration. Patients were randomly allocated to a treatment and a nontreatment group. Treatment consisted of a tapering regimen of methylprednisolone, starting at 24-32 mg.day-1 for a total of seven months, with half the treated group receiving alternate day therapy for all but the first two weeks of treatment. Treated patients were found to have improvement in chest radiography, forced vital capacity (FVC) and diffusion capacity for carbon monoxide.

In a study of disease relapse after corticosteroid withdrawal, chest radiography showed increased changes in 7 out of 10 patients who had a symptomatic relapse, by comparison with 0 out of 5 with no relapse; chest radiography improved in all 10 relapsers when steroids were reintroduced and this was accompanied by an improvement in spirometry [63].

Other studies have, however, shown less significant differences between treated and untreated groups. ZAKI et al. [65] enrolled 183 patients into a controlled, double-blind therapeutic study and found only trends towards a significant improvement in a treated group. Young et al. [66] showed no benefit of treatment at six months or 1-2 yrs.

An inherent weakness of these studies is that mixed groups, including appreciable numbers with "early" disease, were recruited, which meant that a significant percentage of the untreated (and treated) patients would have improved spontaneously, a feature which is well-recognized in sarcoidosis. A second problem is that treatment was not individually tailored, and all patients received the same treatment regimen irrespective of other factors, such as disease extent. These same criticisms apply to the evaluation of the longer term benefits of steroid therapy.

\section{Effect of corticosteroids on long-term outcome}

It is the role of steroids in modulating long-term outcome which has drawn the most disagreement among those involved in treating patients with sarcoidosis. Although the prevention of progressive lung injury is one of the most fundamental goals in sarcoidosis, there have been no properly designed studies which have explored this aspect of management, but a number of studies have purported to do so.
ISRAEL et al. [61] used a three month treatment period of $15 \mathrm{mg} \cdot$ day $^{-1}$, in a placebo-controlled, double-blind study and evaluated outcome at a mean of 5.4 yrs. Young and co-workers [66, 67] compared treatment for six months (six patients) and up to 2 yrs (six patients) against no treatment and assessed outcome at 1-2 yrs and, in a subsequent report, at $10-15 \mathrm{yrs}$ : 11 of the 12 treated patients received no treatment beyond the 2 yrs period. Both of these studies showed no significant differences between treated and untreated groups at the end of the follow-up period. However, neither these nor other studies have attempted to produce maximum improvement and to then titrate the dosage of therapy to maintain that improvement (this also entails an estimate of prevention of disease progression). It is, perhaps, not surprising that a standard regimen administered for a limited period has no effect on outcome 5-10 yrs later; and, indeed, even IsRAEL [68], in a critical editorial in 1987, entitled "Corticosteroid treatment of sarcoidosis - who needs it?" concluded ".....patients frequently relapse after termination of treatment, and close surveillance is necessary for several years afterward". At present, the body of evidence indicates that steroids can modulate disease but that it has not been proven if longer term treatment can prevent disease progression, lung injury and fibrosis.

\section{Inhaled corticosteroids}

Few studies have explored the role of inhaled steroids in the management of sarcoidosis, even though the disease is widely recognized to be "bronchocentric", with the major site of the inflammatory infiltrate involving the peribronchiolar regions and airflow obstruction being a feature of more longstanding disease and, in one study, being present in a significant number of patients at presentation [69]. If pulmonary disease could be modulated by inhaled therapy, there would be less reluctance to intervene with steroids, as the cost/benefit ratio of commencing treatment early would be low. Definitive studies have yet to be performed, although SELRoos [70] reported some success in a small number of patients treated with budesonide. In an open study, 20 patients were treated with up to $1,600 \mu \mathrm{g}$ of budesonide daily for 3-6 months followed by a taper to $400 \mu \mathrm{g}$, if possible, and continued for 18 months. Outcome was assessed at 3-6 monthly intervals by chest radiography, lung function tests and serum angiotensin converting enzyme levels. Fifteen of 16 patients improved symptomatically; 15 of 20 chest radiographs had improved; and 16 patients had increased FVC (but not to statistical significance). Although these results are encouraging and side-effects were minimal (two individuals with hoarse voice), the interpretation of these findings is limited by the lack of a control group and the recruitment strategy, which involved a "run-in" period of only 6 months. Even though "progressive" disease was noted during this period, it is also possible that spontaneous resolution could have followed.

Another study compared 10 patients with symptomatic pulmonary sarcoidosis with a placebo group of 10 
normal individuals and five patients with sarcoidosis. In this series, all 10 patients on active treatment improved symptomatically after budesonide $1,600 \mu \mathrm{g} \cdot \mathrm{day}^{-1}$, but the chest radiographic pattern improved in only 3 out of 10 , and no lung function improvement was observed over the 16 week study period [71]. However, BAL lymphocyte numbers fell in the treated group and the percentage of macrophages with the phenotype associated with immune response suppression (RFD1/D7) was also reduced in the treated group only $[72,73]$. The observation on lymphocyte numbers is matched by a reduction of CD4:CD8 T-cell ratio of bronchoalveolar lymphocytes after inhaler treatment reported in another study [74].

\section{Conclusion}

Corticosteroids are effective in the management of sarcoidosis, by downregulating genes known to play a key role in pathogenesis and by improving indices of disease. Their effect on disease outcome needs further study. The ideal requirements of such a study are: 1) a homogeneous population of patients; 2) disease present for at least one year (more likely to be persistent); 3) predefined outcome measures; 4 ) individualized treatment to maximize and maintain response; 5) comparison with a nontreatment or placebo-treated group; and 6) it will almost certainly need to be multicentre (internationally) and will, therefore, need tightly applied recruitment criteria.

Further longer term studies of inhaled therapy should be undertaken, and should also be double-blind, placebocontrolled and should fulfil the above recommendations.

\section{References}

1. Crystal RG, Bitterman PB, Rennard ST, Hance AJ, Keogh BA. Interstitial lung diseases of unknown cause: disorders characterized by chronic inflammation of the lower respiratory tract. N Engl J Med 1984; 310: 154-165 and 235-244.

2. Thomas PD, Hunninghake GW. Current concepts of the pathogenesis of sarcoidosis. Am Rev Respir Dis 1987; 135: 747-760.

3. Mitchell DN, Scadding JG. Sarcoidosis. Am Rev Respir Dis 1974; 110: 774-802.

4. Daniele RP, Dauber JH, Rossman MD. Immunologic abnormalities in sarcoidosis. Ann Intern Med 1980; 92: 406-416.

5. Boros DL, Experimental granulomatosis. Clin Dermatol 1986; 4: 10-21.

6. Fidler HM, Rook GA, Johnson NM, McFadden J. Mycobacterium tuberculosis DNA in tissue affected by sarcoidosis. Br Med J 1993; 306: 546-549.

7. Bocart D, Lecossier D, De Lassence A, Valeyre D, Battesti $\mathrm{J}-\mathrm{P}$, Hance AJ. A search for mycobacterial DNA in granulomatous tissues from patients with sarcoidosis using the polymerase chain reaction. Am Rev Respir Dis 1992; 145: 1142-1148.

8. Kent DC, Houk VN, Slliot RC, Sokolowski JW, Baker $\mathrm{JH}$, Sorenson K. The definitive evaluation of sarcoidosis. Am Rev Respir Dis 1970; 101: 721-727.

9. Paul WE. The immune system: an introduction. In:
Paul WE, ed. Fundamental immunology. New York, Raven Press, 1989; pp. 3-19.

10. Berzofsky JA. Structural basis of antigen recognition by T-lymphocytes. Implications for vaccines. J Clin Invest 1988; 82; 1811-1817.

11. Mackaness GB. The mechanisms of macrophage activation. In: Mudd S, ed. Infectious Agents and Host Reactions. Philadelphia, W.B. Saunders, 1970; pp. 61-75.

12. Unanue ER. Antigen-presenting function of the macrophage. Ann Rev Immunol 1984; 2: 395-428.

13. Braciale TJ, Morrison LA, Sweetser MT, Sambrook J, Gething M-J, Braciale VL. Antigen presentation pathways to class I and II MHC restricted T-lymphocytes. Immunol Rev 1987; 98; 95-114.

14. Buus S, Sette A, Grey HM. The interaction between protein-derived immunogenic peptides and Ia. Immunol Rev 1987; 98: 115-141.

15. Harding CV, Unanue ER. Antigen processing and intracellular Ia. Possible roles of endocytosis and protein synthesis in Ia function. J Immunol 1989; 42: 12-19.

16. Venet A, Hance AJ, Saltini C, Robinson WS, Crystal RG. Enhanced alveolar macrophage-mediated antigeninduced T-lymphocyte proliferation in sarcoidosis. J Clin Invest 1985; 75: 293-301.

17. Lem VM, Lipscomb MF, Weissler JC, et al. Bronchoalveolar lavage cells from sarcoid patients demonstrate enhanced antigen presentation. J Immunol 1985; 135: 1766-1771.

18. Cantrell D, Davies AA, Londel M, Feldman M, Crumpton MJ. Association of phosphorylation of the T3 antigen with immune activation of T-lymphocytes. Nature 1987; 325: 540-542.

19. Noonan DJ, Isakov N, Theofilopoulos AN, Dixon FJ, Altman A. Protein kinase C-activating phorbol esters augment expression of T-cell receptor genes. Eur $J$ Immunol 1987; 17: 803-807.

20. du Bois RM, Kirby M, Balbi B, Saltini C, Crystal RG. $\mathrm{T}$-lymphocytes that accumulate in the lung in sarcoidosis have evidence of recent stimulation of the T-cell antigen receptor. Am Rev Respir Dis 1992; 145: 12051211.

21. Lecossier D, Valeyre D, Loiseau A, et al. Antigeninduced proliferative response of lavage and blood Tlymphocytes. Am Rev Respir Dis 1991; 144: 861-868.

22. Hance AJ, Douches S, Winchester RJ, Ferrans VJ, Crystal RG. Characterisation of mononuclear phagocyte subpopulations in the human lung by using antibodies: changes in alveolar macrophage phenotype associated with pulmonary sarcoidosis. J Immunol 1985; 134: 284292.

23. Bitterman PB, Saltzman LE, Adelberg J, Ferrans VJ, Crystal RG. Alveolar macrophage replication. One mechanism for the explansion of the mononuclear phagocyte population in the chronically inflammed lung. J Clin Invest 1984; 72: 460-469.

24. Campbell DA, du Bois RM, Butcher RG, Poulter LW. The density of HLA-DR antigen expression on alveolar macrophages is increased in pulmonary sarcoidosis. Clin Exp Immunol 1986; 65: 165-171.

25. Spurzem JR, Saltini C, Kirby M, Konishi K, Crystal RG. Expression of HLA class II genes in alveolar macrophages of patients with sarcoidosis. Am Rev Respir Dis 1989; 140: 89-94.

26. Campbell DA, Poulter LW, du Bois RM. Phenotypic analysis of alveolar macrophages in normal subjects and in patients with interstitial lung disease. Thorax 1986; 41: 429-434. 
27. Eden E, Turino GM. Interleukin-1 from human alveolar macrophages in lung disease. J Clin Immunol 1986; 6: 326-333.

28. Wewers MD, Saltini C, Sellers S. Evaluation of alveolar macrophages for the spontaneous expression of the interleukin-1 beta gene. Cell Immunol 1987; 107: 479-488.

29. Hunninghake GW. Release of interleukin-1 by alveolar macrophages of patients with active pulmonary sarcoidosis. Am Rev Respir Dis 1984; 129: 569-572.

30. Pueringer RJ, Schwartz DA, Dayton CS, Gilbert SR, Hunninghake GW. The relationship between alveolar macrophage TNF, IL-1 and $\mathrm{PGE}_{2}$ release, alveolitis, and disease severity in sarcoidosis. Chest 1993; 103: 832838.

31. Müller-Quernheim J, Pfeifer S, Mannel D, Strausz J, Ferlinz R. Lung-restricted activation of the alveolar macrophage/monocyte in pulmonary sarcoidosis. Am Rev Respir Dis 1992; 145: 187-192.

32. Baughman RP, Strohofer SA, Buchsbaum J, Lower EE. Release of tumor necrosis factor by alveolar macrophages of patients with sarcoidosis. J Lab Clin Med 1990; 115: $36-42$.

33. Foley NM, Millar AB, Meager A, Johnson NMcI, Rook GAW. Tumour necrosis factor production by alveolar macrophages in pulmonary sarcoidosis and tuberculosis. Sarcoidosis 1992; 9: 29-34.

34. Bachwich PR, Lynch JP, Larrick J, Spengler M, Kunkel SL. Tumor necrosis factor production by human sarcoid alveolar macrophages. Am J Pathol 1986; 125; 421-425.

35. Strieter RM, Remick DG, Lynch JP, Spengler RN, Kunkel $\mathrm{S}$. Interleukin-2-induced tumour necrosis factor-alpha $(\mathrm{TNF} \alpha)$ gene expression in human alveolar macrophages and blood monocytes. Am Rev Respir Dis 1989; 139: 335-342.

36. Saltini C, Spurzem JR, Lee JL, Pinkston P, Crystal RG. Spontaneous release of interleukin-2 by lung T-lymphocytes in active pulmonary sarcoidosis is primarily from the Leu3+DR+T-cell subset. J Clin Invest 1986; 77 : 1962-1970.

37. Tazi A, Nioche S, Chastre J, Smiejan JM, Hance AJ. Spontaneous release of granulocyte colony-stimulating factor (G-CSF) by alveolar macrophages in the course of bacterial pneumonia and sarcoidosis: endotoxin-dependent and endotoxin-independent G-CSF release by cells recovered by bronchoalveolar lavage. Am J Respir Cell Mol Biol 1991; 4: 140-147.

38. Hunninghake GW, Crystal RG. Pulmonary sarcoidosis; a disorder mediated by excess helper T-lymphocyte activity at sites of disease activity. $N$ Engl J Med 1981; 305: 429-434.

39. Pinkston P, Bitterman PB, Crystal RG. Spontaneous release of interleukin-2 by lung T-lymphocytes in active pulmonary sarcoidosis. N Engl J Med 1983; 308: 793-800.

40. Semenzato G, Agostini C, Trentin L, et al. Evidence of cells bearing interleukin-2 receptor at sites of disease activity in sarcoid patients. Clin Exp Immunol 1984; 57: 331-337.

41. Costabel U, Bross KJ, Rühle KH, Löhr GW, Matthys H. Ia-like antigens of T-cells and their subpopulations in pulmonary sarcoidosis and in hypersensitivity pneumonitis. Analysis of bronchoalveolar lavage and blood lymphocytes. Am Rev Respir Dis 1985; 131: 337-342.

42. Saltini C, Hemler ME, Crystal RG. T-lymphocytes compartmentalised on the epithelial surface of the lower respiratory tract express the very late activation antigen complex, VLA-1. Clin Immunol Immunopathol 1988; 46: 221-233.
43. Semenzato G, Chilosi M, Cipriani A, et al. Cells and mediators involved in the mechanisms of granuloma formation in patients with granulomatous disorders. In: Yoshida T, Torisu M, eds. Basic Mechanisms of Granulomatous Inflammation. Amsterdam, Elsevier Science Publishers B.V., 1989; pp. 282-298.

44. Chilosi M, Mombello A, Lestani M, Menestrina F, Facchetti F, Semenzato G. Immunohistochemical analysis of cells accounting for granuloma formation. Sarcoidosis 1992; 9: 199-203.

45. Konishi K, Moller DR, Saltini C, Kirby M, Crystal RG. Spontaneous expression of the interleukin-2 receptor gene and presence of functional interleukin-2 receptors on T-lymphocytes in the blood of individuals with active pulmonary sarcoidosis. J Clin Invest 1988; 82: 775781.

46. Saltini C, Pinkston P, Lee JJ, Crystal RG. Role of Thelper cell subsets in expanding the T-cell alveolitis of active pulmonary sarcoidosis. Clin Res 1985; 33: 472A.

47. Hunninghake GW, Gadek JE, Young RC, Kawanami O, Ferrans VJ, Crystal RG. Maintenance of granuloma formation in pulmonary sarcoidosis by T-lymphocytes within the lung. N Engl J Med 1980; 302: 594-598.

48. Itoh A, Yamaguchi E, Kuzumaki N, et al. Expression of granulocyte-macrophage colony-stimulating factor mRNA by inflammatory cells in the sarcoid lung. Am J Respir Cell Mol Biol 1990; 3: 245-249.

49. Itoh A, Yamaguchi E, Furuya K, et al. Correlation of GM-CSF mRNA in bronchoalveolar fluid with indices of clinical activity in sarcoidosis. Thorax 1993; 48: 1230-1234.

50. Kreipe H, Radzun HJ, Heidorn K, et al. Proliferation, macrophage colony-stimulating factor and macrophage colony-stimulating factor-receptor expression of alveolar macrophages in active sarcoidosis. Lab Invest 1990; 62: 697-703.

51. Campbell DA, Poulter LW, du Bois RM. Immunocompetent cells in bronchoalveolar lavage reflect the cell population in transbronchial biopsies in pulmonary sarcoidosis. Am Rev Respir Dis 1985; 132: 13001306.

52. Semenzato G, Chilosi M, Ossi E. Bronchoalveolar lavage and lung histology. Comparative analysis of inflammatory and immunocompetent cells in patients with sarcoidosis and hypersensitivity pneumonitis. Am Rev Respir Dis 1985; 132: 400-404.

53. Devergne O, Emilie D, Peuchmaur M, Crevon MC, D'Agay MF, Galanaud P. Production of cytokines in sarcoid lymph nodes: preferential expression of interleukin-1 beta and interferon-gamma genes. Hum Pathol 1992; 23: 317-323.

54. Munro CS, Campbell DA, du Bois RM, Mitchell DN, Cole PJ, Poulter LW. Dendritic cells in cutaneous, lymph node, and pulmonary lesions of sarcoidosis. Scand J Immunol 1987; 25: 461-467.

55. Munck A, Mendel DB, Smith LI, Orti E. Glucocorticoid receptors and actions. Am Rev Respir Dis 1990; 141: S2-S10.

56. Baughman RP, Strohofer SA, Buchsbaum J, Lower EE. Release of tumor necrosis factor by alveolar macrophages of patients with sarcoidosis. J Lab Clin Med 1990; 115: $36-42$.

57. Robinson BWS, McLemore TL, Crystal RG. Gammainterferon is spontaneously release by alveolar macrophages and lung T-lymphocytes in patients with pulmonary sarcoidosis. J Clin Invest 1985; 74: 1488-1495. 
58. Pinkston P, Saltini C, Muller-Quernheum J, Crystal RG. Corticosteroid therapy suppresses spontaneous interleukin2 release and spontaneous proliferation of lung T-lymphocytes of patients with active pulmonary sarcoidosis. J Immunol 1987; 139: 755-760.

59. Scadding JC, Mitchell DN. In; Sarcoidosis. London, Chapman \& Hall, 1985; 580-590.

60. Selroos O, Sellergren T-L. Corticosteroid therapy of pulmonary sarcoidosis: a prospective evaluation of alternate day and daily dosage in Stage II disease. Scand J Respir Dis 1979; 60: 215-221.

61. Israel HL, Fouts DW, Beggs RE. A controlled trial of prednisone treatment of sarcoidosis. Am Rev Respir Dis 1973; 107: 609-614.

62. Odlum CM, FitzGerald MX. Evidence that steroids alter the natural history of previously untreated progressive pulmonary sarcoidosis. Sarcoidosis 1986; 3: 4046.

63. Baumann MH, Strange C, Sahn SA. Do chest radiographic findings reflect the clinical course of patients with sarcoidosis during corticosteroids withdrawal? AJR 1990; 154: 481-485.

64. Tuner-Warwick M, McAllister W, Lawrence R, Britten A, Haslam PL. Corticosteroid treatment in sarcoidosis: do serial lavage lymphocyte counts, serum angiotensinconverting enzyme measurements and gallium-67 scans help management? Thorax 1986; 41: 903-913.

65. Zaki MH, Lyons HA, Leilop L, Huang CT. Corticosteroid therapy in sarcoidosis. A five year, controlled, followup study. NY State J Med 1987; 87: 496-499.

66. Young RL, Harkerload LE, Lordon RE, Weg JG. Pulmon- ary sarcoidosis: a prospective evaluation of glucocorticoid therapy. Ann Intern Med 1970; 73: 207-212.

67. Harkerload LE, Young RL, Savage PJ, Jenkins DW, Lordon RE. Pulmonary sarcoidosis: long-term followup of the effects of steroid therapy. Chest 1982; 84 87.

68. Israel HL. Corticosteroid treatment of sarcoidosis - who needs it? NY State J Med 1987; 87: 490.

69. Harrison BDW, Shaylor JM, Stokes TC, Wilkes AR. Airflow limitation in sarcoidosis: a study of pulmonary function in 107 patients with newly diagnosed disease. Respir Med 1991; 85: 59-64.

70. Selroos OB. Use of budesonide in the treatment of pulmonary sarcoidosis. Ann NY Acad Sci 1986; 465: 713721.

71. Spiteri MA, Newman SP, Clarke SW, Poulter LW. Inhaled corticosteroids can modulate the immunopathogenesis of pulmonary sarcoidosis. Eur Respir J 1989; 2: 218224.

72. Spiteri M, Clarke SW, Poulter LW. Alveolar macrophages that suppress T-cell responses may be crucial to the pathogenetic outcome of pulmonary sarcoidosis. Eur Respir J 1992; 5: 394-403.

73. Spiteri M, Clarke SW, Poulter LW. Phenotypic and functional changes in alveolar macrophages contribute to the pathogenesis of pulmonary sarcoidosis. Clin Exp Immunol 1988; 74: 359-364.

74. Erkkila S, Froseth B, Hellstrom PE, et al. Inhaled budesonide influences cellular and biochemical abnormalities in pulmonary sarcoidosis. Sarcoidosis 1988; 5: 106110. 